\title{
Practices of health professionals in delivery and birth care
}

\author{
Práticas de profissionais de saúde na assistência ao parto e nascimento
}

Laura Pinto Torres de Melo르. Hilana Dayana Doudou², Antonia Regynara Moreira Rodrigues ${ }^{1}$, Maria Adelaide Moura da Silveira ${ }^{1}$, Eryjosy Marculino Guerreiro Barbosa ${ }^{1}$, Dafne Paiva Rodrigues ${ }^{1}$

Objective: to understand the practices adopted by health professionals in the care of parturient women. Methods: qualitative study conducted in a public hospital with 13 health professionals through semi-structured interviews. Narrative data were organized according to content analysis. Scientific evidence for best practices in delivery and birth care according to recommendations of the World Health Organization, were used as reference. Results: two care contexts were raised: the use of practices backed by scientific evidence and routine practices whose evidence is not favorable to use, denoting the adoption of practices derived from beliefs and knowledge of physicians on duty. Conclusion: professionals had their practices backed by scientific evidence, but they still use strategies whose effectiveness is not guaranteed. There is, therefore, a long way to humanize the care provided during childbirth.

Descriptors: Parturition; Natural Childbirth; Midwifery; Women's Health; Obstetrics.

Objetivo: compreender as práticas adotadas por profissionais de saúde no atendimento à parturiente. Métodos: estudo qualitativo, realizado em uma maternidade pública com 13 profissionais de saúde, a partir de entrevista semiestruturada. Dados narrativos organizados de acordo com o método de análise de conteúdo, tendo como referencial as evidências científicas para boas práticas de atenção ao parto e nascimento, fundamentada nas recomendações da Organização Mundial da Saúde. Resultados: revelaram-se dois contextos assistências: utilização de práticas respaldadas em evidências científicas e práticas rotineiras, cujas evidências não são favoráveis ao uso, o que denota a adoção de práticas oriundas de crenças e saberes de plantonistas. Conclusão: os profissionais apoiavam suas práticas em evidências científicas, porém permaneciam utilizando estratégias cuja eficácia não está garantida, apontando ainda um longo caminho para humanizar a assistência durante a parturição.

Descritores: Parto; Parto Normal; Tocologia; Saúde da Mulher; Obstetrícia.

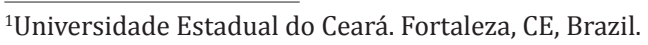

${ }^{2}$ Universidade Federal do Ceará. Fortaleza, CE, Brazil. 


\section{Introduction}

Assistance to labor and birth has undergone profound changes over the years, leaving the home environment to take place in the hospital setting, led by technology and surgical methods, and resulting in the removal of the family and of society from the birth process $^{(1)}$.

A technicist model of attention focused on professionals, with surgical and drug interventions, started to prevail. In such models, professionals and institutions had the control of the whole process, determining rules and rigid routines that sometimes would prevented women from exercising their protagonism during labor and birth ${ }^{(2)}$.

In a move towards overcoming this model, the World Health Organization published a practical guide for normal birth care. Strategies to ensure safe motherhood and humanized care, without risks to women and newborns, where proposed. The proposals aimed to reduce interventions in childbirth care, have the woman as protagonist of the birth itself, incorporating the companion of their choice in the childbirth process and considering the social and emotional dimension in care dynamics, guiding assistance by scientific evidence ${ }^{(3)}$.

In Brazil, the trend to reorganize labor and birth care started with health programs and policies that proclaimed the idea of humanized parturition by several segments. However, despite the efforts to improve the service and the relationship between professionals and users, humanization of the assistance provided to women before, during and after childbirth remains a challenge that health services, especially health workers, should overcome.

The term humanization of birth refers to a multiplicity of interpretations and a broad set of proposed changes in care practices. These are supported on pillars such as evidence-based practice, respect for human rights, appreciation of human experience, resizing of roles and powers in the birth scene, placing the woman and her family as centers of care and the rescue of the physiological and natural characteristics of birth, bringing new and challenging, sometimes conflicting, concepts to the daily routine of services ${ }^{(1)}$.

Labor and delivery comprise a complex and multifaceted interaction between mother and fetus, through a series of physiological and psychological events, by means of which the fetus is expelled from the uterus, leading to the birth of a baby and the formation or expansion of a family ${ }^{(4)}$.

The complexity of factors surrounding delivery and the assistance to this moment has raised questions that go from the quality of obstetric care to the meaning of parturition. Previous studies about the perceptions of professionals and users have revealed that the humanization of labor and birth covers structural aspects and the ethical attitude of professionals, effective interpersonal communication, involvement and mutual respect between professional-parturient-family, since hosting up to hospital discharge $\mathrm{e}^{(1,5-6)}$.

This information strengthens the need for reflection and struggle for recover the natural scenario of birth. This was formerly re-written as a physiological and natural process in women's lives and their families, including health professionals as a key element to implement humanized birth, as they are drivers of this process. This study was developed to respond the following question: how can the routine practices of health professionals during labor, delivery and birth be characterized?

Thus, the objective was to understand the practices adopted by health professionals in the care of parturient women.

\section{Methods}

Qualitative study conducted in a public hospital that provides secondary care located in Fortaleza, Brazil. The choice of this site was supported by the fact that this is a reference to maternal and child care in the municipal network and because it develops programs and projects aimed at humanization of delivery care. 
The study included 13 professionals with superior education, namely, four nurses and nine physicians, who met the following inclusion criteria: having residence or specialization in obstetrics; providing assistance only in the delivery room for at least six months and be working in the period of data collection. Participants were identified by the letter "P", referring to participant, and numbered in chronological order according to the interviews.

Data were collected from March to June, 2013, by applying semi-structured interviews developed by the authors. The interviews consisted of professional identification and information related to practices adopted by professionals during labor and delivery.

For analysis of the interviews, we used the content analysis method ${ }^{(7)}$. This method is a set of analysis techniques of communication that uses systematic procedures and description of the objectives of the content of messages in three phases: 1) Pre-analysis; 2) Exploration of material; 3) Treatment of results, inference and interpretation.

Finally, results were interpreted and subsequently discussed with the literature on the subject. For this, scientific evidence for best delivery and birth care practices according to the recommendations of the World Health Organization were used as reference. Practices were classified into: (A) demonstrably useful practices that should be encouraged; (B) clearly harmful or ineffective practices that should be eliminated; (C) practices for which there is insufficient evidence to support a clear recommendation and which should be used with caution until further research clarifies the matter; (D) practices often used improperly ${ }^{(3)}$.

The study complied with the formal requirements contained in the national and international regulatory standards for research involving human beings.

\section{Results}

The study included 13 professionals of the abovementioned maternity, aged between 30 and 56 years between six males and seven females. Regarding the training time, five had an average of six to 16 years and eight, 23-32 years. As for working time, one professional had only six months, four professionals had from two to seven years, and eight had 10-22 years.

The following thematic class stemmed from data analysis: Birth: the course of labor and delivery. This was composed of 70 recording units distributed in two categories and six subcategories based on the similarities of the interviewees' speeches. In the first category, entitled "Best practices applied to parturient women", favorable practices during labor and childbirth were approached and distributed into four subcategories: non-pharmacological means, warm quiet atmosphere, useful practices in labor and delivery and participation of companions. The second category, entitled "Harmful practices for parturient women", deals with conducts considered inappropriate during labor and delivery and these are distributed into two subcategories: avoidable practices and inappropriate use of interventionist practices.

\section{Category 1: Best practices applied to parturient women}

This category included 41 record units and four subcategories that pointed practices adopted by health professionals that are considered beneficial during labor and delivery.

Practices and actions developed by health professionals offer assistance to women in labor in a humane way, meeting their needs and particularities. These practices involve respect, emotional support, the good relationship between professionals and la- 
boring women, as well as actions that can encourage women to actively participate in their delivery and contribute to pain relief and labor progression.

The use of non-pharmacological means, the preparation of a warm and quiet atmosphere, the development of favorable practices during labor and delivery and the involvement of companions, were all mentioned as good practices. Figure 1 presents the subcategories related to best practices with respective reports of respondents.

The use of such practices by professionals while assisting delivery falls within the category A demonstrably useful practices that should be encouraged, due to its benefits to mothers. These include giving guidance to women on the process of labor and delivery, stimulating non-pharmacological methods for pain relief, the release of diet, encouraging the presence of a companion, always respecting the will and choices of women, and environmental organization.

Among the non-pharmacological means, the Swiss ball, the horse, encouraging the use of upright positions for birth, ambulation, spray shower and massage, were cited as practices to minimize the pain of labor and delivery and, consequently, provide greater comfort and less anxiety.Another good practice mentioned was the reception of women and ater comfort and less anxiety.Another good practice men- tioned was the reception of women and their families in a suitable physical environment, a warm atmosphere that may transmit tranquility, welfare and safety. In this environment, the presence and participation of companions of the preference of mothers until the time of labor and birth is respected.

\section{Category 2: Harmful practices for parturient women}

This category gathered 29 record units distributed into two subcategories. The first described avoidable practices, and the second, the inadequate use of interventionist practices, which list the practices that have no scientific evidence in favor of its use during labor and delivery, but that are present in the reports of professionals (Figure 2).

The listed practices are distributed in three categories. In category B - Clearly harmful or ineffective practices that must be eliminated, such as trichotomy, venous catheterization, enema and oxytocics administration at any time before delivery; in category $\mathrm{C}$ - Practices without enough evidence to support a clear recommendation and that must be used with caution until further research clarifies the matter, namely: early amniotomy and pressuring the uterus fund during labor and, in the category D - Practices often improperly used, which include repeated vaginal examinations.

\begin{tabular}{|c|c|c|c|}
\hline Nonpharmacological means & $\begin{array}{l}\text { Warm and quiet } \\
\text { atmosphere }\end{array}$ & $\begin{array}{c}\text { Useful practices during labor } \\
\text { and delivery }\end{array}$ & Participation of companions \\
\hline $\begin{array}{l}\text { We use the ball and the horse as } \\
\text { a way to stimulate the vertical } \\
\text { position ... (P03). } \\
\text {... leave the patient at ease, for } \\
\text { her walk or use the horse, the ball } \\
\text {... (P04). } \\
\text { Massages, positions, the issue of } \\
\text { taking them to the bathroom, to } \\
\text { take a bath for them to relax... } \\
\text { (P13) }\end{array}$ & $\begin{array}{l}\text {... We try to leave the patient in } \\
\text { an environment with low light } \\
\text { with little noise, as little noise } \\
\text { as possible... (P01). } \\
\text {...She should receive assistance } \\
\text { in a peaceful setting, a warm } \\
\text { atmosphere... (P02). } \\
\text {...Provide a quiet environment } \\
\text { to transmit them security... } \\
(\mathrm{P} 10) .\end{array}$ & $\begin{array}{l}\text {...Explain her what we're doing, } \\
\text { what we will do and what will } \\
\text { happen from then on... (P09). } \\
\text {...Liquid diet or a diet that pregnant } \\
\text { women accept... (P08). } \\
\text {...Respecting her wishes, directions } \\
\text { and options... (P02). }\end{array}$ & $\begin{array}{l}\text { During childbirth, she must be } \\
\text { preferably with a companion... } \\
\text { (P04). } \\
\text {...The companion by her side and } \\
\text { giving her as much comfort as } \\
\text { possible... (P05). } \\
\text {...But I call the companion, } \\
\text { explain him what he can do, I } \\
\text { encourage him to do massage, } \\
\text { I encourage him to be near the } \\
\text { woman... (P03). }\end{array}$ \\
\hline
\end{tabular}

Figure 1 - Best practices applied to parturient women 
These interventionist practices do not favor the birth to occur naturally. The recommendation of the World Health Organization is that they must be used only when there is need, after evaluation and clinical judgment basis. This way, their use will not bring risks for the mother and/or the child, instead of causing it.

It is noteworthy that some of these practices are avoided by professionals. This shows a trend to wards humanized care, avoiding venipuncture, trichotomy, enema, episiorrhaphy and excessive digital vaginal examinations. Others, though, are less frequently practiced but remain present in the routine of professionals. For example, amniotomy, oxytocin use and Kristeller maneuver are some of these practices. Their use require greater awareness and critical reflection from professionals, considering the benefits and safety for mothers and neonates.

\begin{tabular}{|c|c|}
\hline Avoidable practices & Inadequate use of interventionist practices \\
\hline $\begin{array}{l}\text {...We avoid making evacuating enema... } \\
\text { (P02). } \\
\text {...We avoid puncturing a vein of the } \\
\text { patient... (P01). } \\
\text {...We try to avoid excessive digital vaginal } \\
\text { examination... (P01). } \\
\text {...We avoid breaking the bag too early, but } \\
\text { let it break naturally... (P11). } \\
\text {...We avoid episiotomy... (P09). } \\
\text {...We avoid trichotomy... (P02). }\end{array}$ & $\begin{array}{l}\text {...But, sometimes the patient is already very close to giving birth and you see that it's not a forced } \\
\text { move, to hold a little the uterus and press, put a little pressure, I think that's better than using } \\
\text { forceps... (P06). } \\
\text { Amniotomy is something I like to do after seven centimeters, I think that helps a lot...you do } \\
\text { amniotomy and the child is born half an hour later (P06). } \\
\text { In childbirth, if it is taking too long, it is sometimes necessary to use a forceps...to avoid the } \\
\text { child's suffering(P10). } \\
\text { An inadequate practice that we see very often is the use of oxytocin (P10). } \\
\text { It has its indications, but we see a very widespread use, sometime ago oxytocin was even more } \\
\text { frequently used... (P01). }\end{array}$ \\
\hline
\end{tabular}

Figure 2 - Harmful practices for parturient women

\section{Discussion}

One limitation of this study was the fact that it was carried out only with professionals and in a single health institution. It becomes vehement give voice and space for mothers report the care they received during labor and childbirth. It is also necessary to expand the search for the various scenarios where the delivery happens, as a proposal for improvement of obstetric practices to meet the needs of professionals and women experiencing the parturition process. These are suggestions for future research.

Promoting comfort and satisfaction to women is the primary task during labor and delivery. Actions that have these goals involve the appreciation of phy- siological birth, the appropriate use of technology, the maintenance of favorable environments, the use of non-pharmacological practices for pain relief and granting women more control over childbirth ${ }^{(8)}$.

The practical guide for assistance to normal childbirth of the World Health Organization proposes rational and critical care practices, restricting interventionist practices to cases where such practices are really necessary. Furthermore, the guide encourages vaginal delivery, breastfeeding in the immediate postpartum period, the rooming-in (mother and newborn), the presence of the father and/or another companion during the birth process, and the role of obstetric nurses in the care of normal deliveries ${ }^{(3)}$.

Current studies show a growing trend of parti- 
cipation of obstetric nurses in normal birth care. Their continued support throughout labor and normal delivery promotes positive outcomes and less technical and surgical interventions, thus preserving the maternal and fetal well-being, as well as ensuring a safe, personalized and humanized experience ${ }^{(2,9-10)}$.

A research conducted on the basis of scientific evidence of interventions routinely used in the labor and delivery process in the United States (epidural analgesia, oxytocin use, amniotomy and episiotomy) found that these are widely used by professionals and the routine use of these interventions disturb the normal physiological processes of labor and birth, increasing complications for women and their babies. It was showed still that the best care is the one that promotes, supports and protects the physiology of labor and birth and ensures safe childbirth. Women should be fed, have the heart rate of the baby evaluated with intermittent auscultation, have access to a wide variety of ways to ease the pain and give birth in harmonious environments that respect the natural time for evolution of delivery ${ }^{(11)}$.

Humanizing childbirth care means, therefore, granting women the main focus of care. This includes creating spaces for them to exercise their autonomy throughout the process, allowing a companion of their choice, telling the patient the procedures to be undertaken, respecting all their rights and labor physiology, avoiding unnecessary interventions, recognizing the social and cultural aspects of labor and birth, offering emotional support to women and their families, facilitating the creation of family bonding and the mother-child bond ${ }^{(1,12)}$. Thus, in this perspective, women become protagonists of their birth and the main component of maternity ${ }^{(13)}$.

Among the changes related to the humanization of childbirth, the physical structure of the place where delivery will happen is very important. Ambiance is responsible for the sense of welcoming, support and warmth, allowing women to experience the birth as a pleasurable experience ${ }^{(5,14)}$. In this study, the com- mitment of professionals to provide a warm and quiet environment in which mothers may feel comfortable to experience labor and the birth of their child strengthened the strategies used to humanize assistance.

The speeches of professionals in this study also mentioned delivery and birth care practices such as: respecting the wishes and needs of the women, the establishment of communication and orientation and recognition of the importance of companion at the moment of delivery. These practices present scientific evidence their beneficial results for labor and childbirth. They involve tranquility, security and increased confidence to the mother, and should therefore be encouraged, converging towards the humanization of care for women during childbirth ${ }^{(14)}$.

In the opinion of respondents, the companion was defined as a key element to provide emotional support to parturient women. They encourage to experience labor and delivery in a more tranquil manner, reducing anxiety and bringing the birth process as close to families as possible. In this respect, the presence of companions is very important for the safety and comfort provided to parturient woman, revealing greater satisfaction and tranquility ${ }^{(6)}$.

The good practices mentioned by professionals in this study included encouragement to upright positions, walking, massages and baths, non-invasive and non-pharmacological methods aiming at the welfare and relief of pain, and respecting the women's wishes and choices. This result shows the knowledge of these professionals and the application of some practices leading to humanized care, in line with the scientific evidence presented in category A.

In studies evaluating the practices used for pain relief during labor, ambulation, proper breathing, the use of the Swiss ball, massages, shower or immersion, the use of the horse, music therapy, and aromatherapy were cited by mothers as good practices to minimize pain and to help to make the birth process more relaxing and enjoyable ${ }^{(6,15)}$.

Furthermore, a systematic review concluded 
that practices such as walking and vertical positions in the first stage of labor reduce the time spent in labor, the risk of cesarean delivery, the need for epidural. These practices have not been associated with any negative effect for mothers and babies ${ }^{(16)}$. Regarding the bath, a randomized clinical trial conducted in the United States found that, in addition to the physical hygiene, this is an strategy that is easy to implement, has favorable cost-benefit and is effective for reducing pain during labor ${ }^{(17)}$.

It is important that health professionals inform the benefits of the techniques adopted during childbirth. The decision to use or not is entirely up to women. They must choose how they want labor happen, free to decide as the protagonists of the whole process of giving birth.

Fluid and food restriction during labor is a practice recognized by the World Health Organization as often inappropriately used. However, in the present study, professionals reported that mothers are allowed to eat whatever they chose, which opposed to previous research' findings ${ }^{(18)}$ stating that one of the practices that are improperly used in normal delivery is routine fasting. This brings discomfort to the mother and risks to the fetus due to the reduction of blood glucose levels. Therefore, water and food should be offered according to the conditions and the evolution of labor. This is actually recommended for low-risk pregnant women during the active phase of labor.

Episiotomy is another practice cited in previous studies ${ }^{(19)}$ as improperly used and often without indication. In the present study, it is commendable that this practice has been avoided by professionals.

It was noticed also that venipuncture, trichotomy, enema and excessive vaginal examinations were avoided by professionals, as these are clearly harmful or ineffective practices according to the recommendations of the World Health Organization. This gives evidence of understanding and awareness of professionals towards seeking the humanization of the care provided to women during childbirth. However, some assistance methods that lack scientific evidence are apparent. They are the Kristeller maneuver and amniotomy, and the clearly negative use of oxytocin ${ }^{(3)}$.

The indiscriminate use of oxytocin was mentioned by professionals as improper. Scientific evidence classify the use of oxytocin at any time of labor as clearly harmful and should be avoided or used only when strictly necessary and judiciously in order to avoid risks to women and newborns ${ }^{(3.19)}$.

The reports show that the Kristeller maneuver, a practice without enough evidence for a clear recommendation, is still used by professionals as a method to accelerate labor and birth. The guide of the World Health Organization considers this maneuver, or any other similar, a harmful and risky practice ${ }^{(3)}$. The frequency of this procedure is due to the lack of humanized practices during labor. Women should be encouraged to give birth in the position that they prefer ${ }^{(19)}$.

Regarding amniotomy, two realities were identified: professionals who wait for the natural rupture of membranes and professionals who opt for the procedure of amniotomy. This is a practice that should be delayed until the end of the delivery because it is an invasive procedure that entails risks, especially regarding maternal and fetal infections. Amniotomy, tough, is indicated in the event of doubt as to the color of the amniotic fluid and possible fetal suffering ${ }^{(19)}$. One of the aspects revealed in this study was that, in the unit studied, the opinion of some workers became real and superior to the guidelines of the World Health Organization. It seems clear that the adoption of practices depends upon the belief and knowledge of physicians.

This study showed that delivery care was linked mainly to availability, sensitivity, commitment and work of professionals. In this regard, we note that the attitude of professionals is a threshold between humanized delivery care and the perpetuation of a technical assistance. Professionals are essential to ensure a safe and pleasurable parturition, in which the resources used should consider risks and benefits, in addition to providing comfort of mothers and respecting their desire and autonomy to make decisions about their delivery. 
It is believed that this study deepens the knowledge in obstetrics and raises reflections on the need to improve the labor and birth care practices, according to scientific basis, and aiming to meet the specific needs of each woman, adding theory, technique and humanization to the care provided to the mother-child-family system.

\section{Conclusion}

The data showed the awareness of professionals on the needs and rights of women as a major factor for qualified and safe care to parturient women, their children and families. Humanized care relied on offering food and fluids, preparing a warm and quiet environment, giving information on the procedures to be performed and the process of labor and respecting their will in relation to adoption of positions and choice of a companion, who comforts and encourages the empowerment of women.

Professionals believe that practices such as venipuncture, enema, excessive vaginal examinations, trichotomy and episiotomy should be avoided during childbirth care. In turn, there is much to advance towards humanize care to delivery and birth. This is because practices such as Kristeller maneuvers, the use of oxytocin and amniotomy are still found in the reports as resources to accelerate birth and prevent fetal distress.

\section{Collaborations}

Melo LPT, Doudou HD and Rodrigues DP contributed to the project design, collection, organization, analysis and interpretation of data, writing and approving the final version of the article. Rodrigues ARM, Silveira MAM and Barbosa EMG contributed to writing the article, relevant critical review of the content and approval of the final version to be published.

\section{References}

1. Souza TG, Gaiva MAM, Modes PSA. A humanização do nascimento: percepção dos profissionais de saúde que atuam na atenção ao parto. Rev Gaúcha Enferm. 2011; 32(3):479-86.

2. Ministério da Saúde (BR). Humanização do parto e do nascimento. Brasília: Ministério da Saúde; 2014.

3. Organização Mundial da Saúde. Assistência ao parto normal: um guia prático. Genebra: Organização Mundial da Saúde; 1996.

4. Ricci SE. Enfermagem materno-neonatal e saúde da mulher. Rio de Janeiro: Guanabara Koogan; 2015.

5. Monte ML, Gomes JS, Amorim LMA. Percepção das puérperas quanto ao parto humanizado em uma maternidade pública de Teresina-PI. Rev Interdisc. 2011; 4(3):20-4.

6. Rocha FAA, Fontenele FMC, Carvalho IR, Rodrigues IDCV, Sousa RA, Ferreira Júnior AR. Care during labor and birth: mothers' perception. Rev Rene. 2015; 16(6):782-9.

7. Bardin L. Análise de conteúdo. Lisboa: Edições 70; 2010.

8. Silva LM, Oliveira SMJV, Silva FMB, Alvarenga MB. Using the Swiss ball in labor. Acta Paul Enferm. 2011; 24(5):656-62.

9. Caus ECM, Santos EKA, Nassif AA, Monticelli M. The process of giving birth assisted by obstetrician nurse in a hospital context: mean for the parturientes. Esc Anna Nery. 2012; 16(1):34-40.

10. Hodnett ED, Gates S, Hofmeyr GJ, Sakala C. Continuous support for women during childbirth. Cochrane Database Sys Rev [Internet]. 2013 [cited 2016 July 13]; (7):CD003766. Available from: http://onlinelibrary.wiley.com/ doi/10.1002/14651858.CD003766.pub3/t;jse ssionid=E1D56A46DFDA9CF36BCDFB18DCDE 2B00.f03t03

11. Lothian JA. Healthy birth practice: avoid interventions unless they are medically necessary. J Perinat Educ. 2014; 23(4):198-206. 
12. Capilé CS, Azevedo AL, Silva, AS. Bittencourt CSS, Azevedo PC. Enfermagem e humanização no cuidado à mulher durante o parto. Rev Baiana Enferm. 2011; 25(2):155-60.

13. Cunha ACB, Santos C, Gonçalves RM. Concepções sobre maternidade, parto e amamentação em grupo de gestantes. Arq Bras Psicol. 2012; 64(1):139-55.

14. Andrade MAC, Lima JBMC. O modelo obstétrico e neonatal que defendemos e com o qual trabalhamos. In: Ministério da Saúde (BR). Humanização do parto e do nascimento. Brasília: Ministério da Saúde; 2014. p.19-46.

15. Frello AT, Carraro TE, Barnardi MC. Cuidado e conforto no parto: estudos na enfermagem brasileira. Rev Baiana Enferm. 2011; 25(2):17384.
16. Lawrence A, Lewis L, Hofmeyr GJ, Styles C. Maternal positions and mobility during first stage labor. Cochrane Database Syst Rev [Internet]. 2013 [cited 2016 July 13]; (2):CD003934. Available from: http://onlinelibrary.wiley.com/ doi/10.1002/14651858.CD003934.pub2/ abstract

17. Lee SL, Liu CY, Lu YY, Gau ML. Efficacy of warm showers on labor pain and birth experiences during the first labor stage. J Obstet Gynecol Neonatal Nurs. 2013; 42(1):19-28.

18. Busanello J, Lunardi Filho WD, Kebber NPC, Lunardi VL, Santos SS. Participação da mulher no processo decisório no ciclo gravídico - puerperal: revisão integrativa do cuidado de enfermagem. Rev Gaúcha Enferm. 2011; 32(4):807-14.

19. Moura FMJSP, Carneiro AMM, Silva JC, Dantas LS, Moura LJSP, Castro AED. Percepção das puérperas sobre o parto normal em uma maternidade. Rev Enferm UFPI. 2012; 3(1):194-200. 